\title{
Serum interleukin-17 and estradiol levels in postmenopausal women in relation to osteoporosis
}

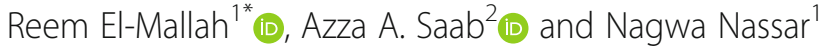

\begin{abstract}
Background: In post-menopausal women, estrogen deficiency leads to instability between bone formation and resorption which is regulated by osteoclastogenic cytokines leading to resorption. Interleukin-17 (IL-17) a proinflammatory cytokine has been found as an important regulator of osteoclast-genesis induced by estrogen deficiency in favor of bone loss in animal studies.

The study aimed to evaluate levels of IL-17 and estrogen (E2) in relation to bone mineral density (BMD) and risk of fracture in postmenopausal women with and without osteoporosis.

Results: IL-17 levels were significantly higher and E2 levels were significantly lower in the osteoporotic group compared to the non-osteoporotic group ( $P$ value $\leq 0.01$ ). There was a highly significant difference in DEXA score and FRAX index between two groups: with higher values of FRAX and lower values of DEXA score among osteoporotic group ( $P$ value $\leq 0.01$ ). IL-17 was inversely correlated to estrogen level and highly significant negative correlation with DEXA as well as a highly significant positive one with FRAX index. IL-17 serum level was able to diagnose osteoporosis at a cutoff level of $>80 \mathrm{pg} / \mathrm{mL}$ with 100\% sensitivity, 100\% specificity, 100\% positive predictive value (PPV), and 100\% negative predictive value (NPV).
\end{abstract}

Conclusions: Serum IL-17 was significantly elevated in osteoporotic postmenopausal women when compared to healthy postmenopausal ones and was inversely correlated with estrogen level and DEXA.

Keywords: Interleukin-17, Osteoporosis, Serum estradiol, DEXA

\section{Background}

Osteoporosis is a complex skeletal disease distinguished by low bone mineral density (BMD) and micro-architectural decay of bone tissue with subsequent fragility [1].

Osteoporosis is either primary or secondary to an identifiable cause as drug, or disease. The primary type includes either type I (postmenopausal) or type II (senile) osteoporosis. The first starts at menopause and occurs predominantly in trabecular bone. It is a consequence of estrogen shortage after menopause. The second type starts 4-8 years later and shows signs of a continual loss of both

\footnotetext{
* Correspondence: reemelmallah@gmail.com

'Department of Physical Medicine, Rheumatology, and Rehabilitation, Faculty of Medicine, Ain Shams University, Cairo, Egypt

Full list of author information is available at the end of the article
}

trabecular and cortical bone. It is predominantly credited to downgraded bone formation [2].

With an escalating aging population, osteoporosis and related fractures are an imperative community health issue that put a huge economic burden on health service supplies.

Bone undergoes endless remodeling which is a fundamental process for healthy bone development. This remodeling is founded on an equilibrium between osteoclastogenic bone resorption and osteoblastogenic bone formation. Mesenchymal stem cells form osteoblast to deliver extracellular bone matrix while monocytic lineage is the source of osteoclasts secreting bone resorptive factors. In post-menopausal women, bone resorption surge, with a drop of bone mineral density (BMD) [3].

\section{Springer Open}

(๑) The Author(s). 2021 Open Access This article is licensed under a Creative Commons Attribution 4.0 International License, which permits use, sharing, adaptation, distribution and reproduction in any medium or format, as long as you give appropriate credit to the original author(s) and the source, provide a link to the Creative Commons licence, and indicate if changes were made. The images or other third party material in this article are included in the article's Creative Commons licence, unless indicated otherwise in a credit line to the material. If material is not included in the article's Creative Commons licence and your intended use is not permitted by statutory regulation or exceeds the permitted use, you will need to obtain permission directly from the copyright holder. To view a copy of this licence, visit http://creativecommons.org/licenses/by/4.0/. 
The pathogenesis of bone loss provoked by estrogen shortage is controlled by osteoclastogenic cytokines secreted by bone marrow stromal cells, osteoblasts, or activated $\mathrm{T}$ cells.

These include receptor activator of nuclear factor $\mathrm{k}-\mathrm{B}$ ligand (RANKL), TNF $\alpha$, IL-6, and IL-17, and contribute to osteoclast differentiation, proliferation, and maturation [4].

Estrogen (E2) guards bone via two core processes: firstly, it provokes osteoprotegerin (OPG) expression in osteoblasts with an anti-osteoclastogenesis role by binding to RANK, the primary differentiation factor for osteoclasts, thus blocking RANKL-RANK binding through it, and secondly, by initiation of osteoclast apoptosis through Fas-ligand signaling. Furthermore, E2 alters the bone marrow leading to a decrease in the number of $\mathrm{B}$ lymphocytes, the manufacturer of RANKL [5].

Interleukin-17 (IL-17) a proinflammatory cytokine formed by Th17 cells [6] and promotes the expression of RANKL on osteoblasts and synoviocytes and potentiates RANK signaling in osteoclasts thereby promoting bone destruction [7]. IL-17 is one of the contributor of bone worsening in long-established auto-immune disorders associated with bone loss [8], many inflammatory disorders [9], and has been found as a crucial regulator of osteoclastogenesis associated with estrogen deficiency in animal studies [5].

This study aimed to evaluate the levels of IL-17 and estrogen in relation to bone mineral density and risk of fracture in postmenopausal women with and without osteoporosis.

\section{Methods}

This study included sixty postmenopausal females: $30 \mathrm{di}-$ agnosed as having primary post-menopausal osteoporosis and 30 without osteoporosis. According to the World Health Organization (WHO) definition of osteoporosis for post-menopausal women based on DEXA measurements [10]. Patients were engaged in the study from January 2020 to June 2020.

Exclusion criteria included patients with secondary osteoporosis such as renal failure, malignancy, gastrointestinal abnormalities, thyroid, and parathyroid diseases, osteomalacia, and patients on treatment of osteoporosis. Other causes that may affect the level of IL-17 such as inflammatory autoimmune diseases were also excluded. Written informed consent was taken from all patients and approval from the ethical committee was obtained.

All participants underwent the following:

\section{Full medical history taking}

Full medical history taking with consideration to the following: current cigarette smoking, early menopause, low intake of diet rich in calcium and vitamin $\mathrm{D}$, shortening over time, recurrent falls, previous fractures, inadequate physical activity, medical history of drugs, and activities of daily living (ADL) using the Katz ADL. This index ranks adequacy of performance of six functional domains (bathing, dressing, toileting, transferring, continence, and feeding). Patients were scored yes/no for independence in each of the six functions. A score of 6 indicates full function, 4 indicates moderate impairment, and 2 or less indicates severe functional impairment [11].

\section{Clinical examination}

A. General examination: including body weight and body height. Body mass index (BMI) defined as: BMI $=$ WEIGHT (in kg)/height (in $\mathrm{m}^{2}$ ).

B. Local examination with emphasis on the following:

- Back examination as tenderness, loss of height, and kyphosis (vertebral fracture), scoliosis, or lordosis

- Hip examination as tenderness, shortening, or external rotation of hip (hip fracture)

- Weakness of the lower extremity muscles that might lead to falls

\section{Radiological investigations}

A. Bone densitometry (using DEXA scan): BMD in the lumbar spine (L1-4) by dual energy X-ray absorptiometry (DEXA). T score was assessed. According to the World Health Organization (WHO) definition of osteoporosis based on DEXA measurements, osteoporosis is categorized according to T score into as follows: Normal -1.0 and above, Osteopenia -1.0 to -2.5 , Osteoporosis -2.5 and below, Severe "established" osteoporosis -2.5 and below plus one or more osteoporotic fracture(s) [12].

According to $\mathrm{T}$ score patients were split into two groups as follow: Group A: 30 postmenopausal with osteoporosis ( $T$ score less than -2.5 ), group $B: 30$ postmenopausal without osteoporosis ( $\mathrm{T}$ score greater than $-1)$.

B. Fracture assessment by FRAX: Fracture assessment was done for both groups using fracture risk assessment tool (FRAX), to assess the10-year probability of a major osteoporotic fracture either in the hip, spine, or wrist [13]. FRAX is a permitted, internet-based computer algorithm that can be retrieved through (http://www.shef.ac.uk/FRAX) [13]. 
C. Plain X-ray over spine antero-posterior and lateral view to exclude any pathology or fracture

\section{Laboratory investigations}

Ten milliliters of venous blood were withdrawn from each subject under complete aseptic condition. Erythrocyte sedimentation rate (ESR) (standard Westergren method), C-reactive protein (CRP) (nephelometric assay), liver and kidney functions, thyroid-stimulating hormone (TSH), and parathyroid hormone (PTH) were measured to exclude secondary causes. Estradiol (E2) was measured by electrochemiluminescence on the Cobas system by Roche Diagnostics, GMBH, Sandhofer Str. 116, 68305 Mannheim, Germany. Interleukin-17A concentration was measured using Invitrogen $^{\text {ti }}$ e Bioscience $^{\mathrm{Tm}}$ IL-17 Platinum ELISA Kit (Catalog Number BMS 2017) supplied by Thermo Fisher Scientific (Thermo-Scientific, 168 Third Avenue, Waltham, MA, USA) according to the manufacturer instructions.

\section{Statistical analysis}

The data were analyzed by SPSS program version 20 . Data were displayed using mean, standard deviation, and range for quantitative variables that are normally distributed and as median and IQR (percentiles) in case of skewed data. Comparison between two groups is performed using independent $t$ test, ANOVA for comparing more than two variables, and Chi-square test for comparison of qualitative data. Pearson's correlation was used to test the relation between two numeric variables. $P$ value $\leq 0.05$ is statistically significant and $P \leq 0.01$ is highly significant.

\section{Results}

This cross-sectional study was conveyed on 60 postmenopausal women. Their age ranged between 46.6 and 68.1 years with mean \pm SD of $59.31 \pm 6.38$ years. The duration of menopause ranged between 5 and 22 years with mean of $11.27 \pm 4.92$ years while BMI ranged between 21.5 and 40.9 with mean \pm SD of $32.2 \pm 5.15$. Twenty percent of post-menopausal osteoporotic group had history of fracture, while $40.0 \%$ of cases had history of fracture in the non-osteoporotic group. Activities of daily living (ADL) ranged between 4 and 6 with mean \pm SD of 5.07 \pm 0.70 in both groups. Patients were divided into two groups based on DEXA measurements: group A, 30 postmenopausal females with osteoporosis ( $\mathrm{T}$ score less than -2.5 ); group B, 30 postmenopausal females without osteoporosis ( $\mathrm{T}$ score greater than -1 ).

On comparing between the osteoporotic group and non-osteoporotic group regarding demographic data (age, menopause duration and BMI, history of fracture and ADL), there was no statistical difference between both groups. A non-significant statistical difference was also found when comparing each of vertebral examination (tenderness, deformity as scoliosis, and kyphosis) and hip examination (pain, tenderness, limitation of movement) between the two groups (Table 1).

On comparing between osteoporotic and nonosteoporotic subjects regarding DEXA score and FRAX index, there was a highly significant statistical difference between the two groups: with higher values of FRAX and lower values of DEXA score among the osteoporotic group (Table 2).

Regarding laboratory data, no statistically significant difference was found between the 2 groups as regards each of ESR, CRP, and PTH. On the other hand, IL17 levels were significantly higher and estradiol levels were significantly inferior in the osteoporotic group compared to the non-osteoporotic group ( $P$ value $\leq 0.01$ ) (Table 3 ).

On performing correlation study between each of E2, IL-17, DEXA score, and FRAX in relation to the clinical

Table 1 Comparison between osteoporotic group and non-osteoporotic group regarding demographic data

\begin{tabular}{|c|c|c|c|c|c|c|}
\hline & & Non-osteoporotic group & Osteoporotic group & Test value & $P$ value & Sig. \\
\hline & & No. $=30$ & No. $=30$ & & & \\
\hline \multirow[t]{2}{*}{ Age (years) } & Mean \pm SD & $57.19 \pm 6.86$ & $61.44 \pm 5.24$ & -1.909 & 0.067 & NS \\
\hline & Range & $46.6-68.1$ & $51.4-69.9$ & & & \\
\hline \multirow[t]{2}{*}{ Duration of menopause } & Mean \pm SD & $10.00 \pm 5.41$ & $12.53 \pm 4.17$ & -1.436 & 0.162 & NS \\
\hline & Range & $5-22$ & $6-19$ & & & \\
\hline \multirow[t]{2}{*}{ BMl } & Mean \pm SD & $32.80 \pm 5.87$ & $31.60 \pm 4.36$ & 0.636 & 0.530 & NS \\
\hline & Range & $21.5-40.9$ & $23.8-36.7$ & & & \\
\hline \multirow[t]{2}{*}{ History of fracture } & No & $18(60.0 \%)$ & $24(80.0 \%)$ & $1.429^{*}$ & 0.232 & NS \\
\hline & Yes & $12(40.0 \%)$ & $6(20.0 \%)$ & & & \\
\hline \multirow[t]{2}{*}{ ADL } & Mean \pm SD & $5.27 \pm 0.80$ & $5.07 \pm 0.70$ & 0.728 & 0.473 & NS \\
\hline & Range & $4-6$ & $4-6$ & & & \\
\hline
\end{tabular}

$P$ value $>0.05$, non-significant; $P$ value $\leq 0.05$, significant; $P$ value $\leq 0.01$, highly significant independent $t$ test ${ }^{*}$ Chi-square test $B M I$ body mass index, $A D L$ activities of daily living 
Table 2 Comparative statistics between the 2 groups regarding radiological data

\begin{tabular}{|c|c|c|c|c|c|c|}
\hline \multicolumn{2}{|c|}{ Radiological data } & \multirow{2}{*}{$\begin{array}{l}\text { Non-osteoporotic group } \\
\text { No. }=\mathbf{3 0} \\
-0.8 \pm 0.07\end{array}$} & \multirow{2}{*}{$\begin{array}{l}\text { Osteoporotic group } \\
\text { No. }=\mathbf{3 0} \\
-1.26 \pm 0.18\end{array}$} & \multirow{2}{*}{$\begin{array}{l}\text { Test value } \\
9.545 \text {. }\end{array}$} & \multirow{2}{*}{$\begin{array}{l}P \text { value } \\
0.000\end{array}$} & \multirow{2}{*}{$\begin{array}{l}\text { Sig. } \\
\text { HS }\end{array}$} \\
\hline DEXA score & Mean \pm SD & & & & & \\
\hline & Range & $-0.62-0.88$ & $-1.07-1.7$ & & & \\
\hline \multirow[t]{2}{*}{ FRAX } & Median (IQR) & $1.1(0.6-1.6)$ & $0.3(0.2-0.4)$ & $-3.934^{\neq}$ & 0.000 & HS \\
\hline & Range & $0.4-1.9$ & $0.1-1.5$ & & & \\
\hline
\end{tabular}

$P$ value $\leq 0.05$, non-significant; $P$ value $\leq 0.05$, significant; $P$ value $\leq 0.01$, highly significant

-Independent $t$ test; ${ }^{\neq}$Mann-Whitney test

DEXA dual energy X-ray absorptiometry, FRAX fracture risk assessment tool

and laboratory data of participant cases, there was a significant negative correlation between E2 level, age, and menopause duration, while there was a highly significant positive correlation between FRAX and each of age and duration of menopause as shown in Table 4.

Conversely, IL-17 had a highly significant statistical negative correlation with bone mineral density (DEXA score), as well as a highly significant positive one with FRAX index. On the contrary, E2 levels showed a highly significant positive correlation with DEXA scores and a negative one with FRAX index. A highly significant negative correlation between IL-17and E2 serum levels in all postmenopausal participants was found (Table 5) (Fig. 1a, b, c, d).

Receiver operating characteristic (ROC) curve was applied to determine the best cutoff level of IL-17 that discriminates between osteoporotic and non-osteoporotic group was $80 \mathrm{pg} / \mathrm{mL}$ at which sensitivity was $100 \%$, specificity $100 \%$, positive predictive value (PPV) $100 \%$, negative predictive value (NPV) $100 \%$, with an area under the curve 1.00. On performing ROC curve, DEXA score diagnosed osteoporosis at a cutoff level of $\leq 0.875$ with $100 \%$ sensitivity, $100 \%$ specificity, $100 \%$ positive predictive value (PPV), and 100\% negative predictive value
(NPV), with an area under the curve of 1.00 , whereas FRAX diagnosed osteoporosis at a cutoff level of $>0.4$, with $93.33 \%$ sensitivity, $80 \%$ specificity, $82.4 \% \mathrm{PPV}$, and 92.3\% NPV with an AUC of 0.92.

\section{Discussion}

Postmenopausal osteoporosis represents an interaction between estrogen scarcity and augmented immune reactivity. T cells are the IL-17 source, while its receptor is expressed on fibroblasts, osteoblasts, chondrocytes, macrophages, dendritic, as well as on endothelial, and most parenchymal cells [14]. IL-17 is one of contributor of bone deterioration in long-established auto-immune inflammatory disorders associated with bone loss including psoriasis, rheumatoid arthritis, systemic sclerosis, and systemic lupus erythematosus $[6,9,15]$.

This study aimed to evaluate the levels of IL-17 and estrogen in relation to bone mineral density and risk of fracture in postmenopausal women with and without osteoporosis.

In the present study, IL-17 levels were significantly higher and estradiol levels were significantly lower in the osteoporotic group compared to the non-osteoporotic group $(P$ value $\leq 0.01)$

Table 3 Comparative statistics between the 2 groups regarding laboratory data

\begin{tabular}{|c|c|c|c|c|c|c|}
\hline \multirow[t]{2}{*}{ Investigations } & & \multirow{2}{*}{$\begin{array}{l}\text { Non-osteoporotic group } \\
\text { No. }=30\end{array}$} & \multirow{2}{*}{$\begin{array}{l}\text { Osteoporotic group } \\
\text { No. }=\mathbf{3 0}\end{array}$} & \multirow[t]{2}{*}{ Test value } & \multirow[t]{2}{*}{$P$ value } & \multirow[t]{2}{*}{ Sig } \\
\hline & & & & & & \\
\hline \multirow[t]{2}{*}{ ESR } & Mean \pm SD & $10.71 \pm 3.14$ & $9.66 \pm 2.55$ & $1.002 \cdot$ & 0.325 & NS \\
\hline & Range & $5.2-14.6$ & $5.7-14$ & & & \\
\hline \multirow[t]{2}{*}{ CRP } & Mean \pm SD & $1.97 \pm 0.65$ & $1.90 \pm 0.72$ & 0.294 & 0.771 & NS \\
\hline & Range & $1-2.9$ & $1-2.9$ & & & \\
\hline \multirow[t]{2}{*}{ PTH } & Mean \pm SD & $43.77 \pm 14.27$ & $40.60 \pm 15.85$ & $0.576 \bullet$ & 0.569 & NS \\
\hline & Range & $17.9-64.1$ & $13.4-63.9$ & & & \\
\hline \multirow[t]{2}{*}{ Estradiol (E2) } & Median (IQR) & 240 (150-300) & $20(5-25)$ & $4.635^{\neq}$ & 0.000 & HS \\
\hline & Range & $75-500$ & $4-100$ & & & \\
\hline \multirow[t]{2}{*}{ IL-17 } & Median (IQR) & $60(50-60)$ & $280(240-300)$ & $4.696^{\neq}$ & 0.000 & HS \\
\hline & Range & $45-80$ & $160-480$ & & & \\
\hline
\end{tabular}

$P$ value $\leq 0.05$, non-significant; $P$ value $\leq 0.05$, significant; $P$ value $\leq 0.01$, highly significant

-Independent $t$ test

${ }^{*}$ Mann-Whitney test

ESR erythrocyte sedimentation rate, CRP C-reactive protein, PTH parathyroid hormone, IL-17 interleukin-17 
Table 4 Correlation study between IL-17, E2, radiological data, and different studied variables in postmenopausal women

\begin{tabular}{|c|c|c|c|c|c|c|c|c|}
\hline & \multicolumn{2}{|l|}{ Estrogen } & \multicolumn{2}{|l|}{ IL-17 } & \multicolumn{2}{|c|}{ DEXA score } & \multicolumn{2}{|l|}{ FRAX } \\
\hline & $r$ & $P$ value & $r$ & $P$ value & $r$ & $P$ value & $r$ & $P$ value \\
\hline Age (years) & $-0.407^{*}$ & 0.026 & 0.254 & 0.176 & -0.232 & 0.217 & $0.584^{* *}$ & 0.001 \\
\hline Duration of menopause & $-0.394^{*}$ & 0.031 & 0.212 & 0.262 & -0.193 & 0.308 & $0.553^{* *}$ & 0.002 \\
\hline BMI & 0.192 & 0.309 & -0.100 & 0.598 & 0.083 & 0.663 & -0.298 & 0.110 \\
\hline ADL & 0.164 & 0.387 & -0.121 & 0.523 & 0.069 & 0.716 & -0.051 & 0.790 \\
\hline ESR & 0.076 & 0.690 & -0.259 & 0.166 & 0.236 & 0.209 & -0.109 & 0.568 \\
\hline CRP & -0.014 & 0.940 & -0.051 & 0.790 & -0.075 & 0.693 & -0.066 & 0.728 \\
\hline PTH & -0.004 & 0.982 & -0.157 & 0.407 & -0.007 & 0.969 & -0.163 & 0.389 \\
\hline
\end{tabular}

$P$ value $\leq 0.05$, non-significant; $P$ value $\leq 0.05$, significant; $P$ value $\leq 0.01$, highly significant

$r$ Spearman correlation coefficient, $B M I$ body mass index, $A D L$ activities of daily living, ESR erythrocyte sedimentation rate, $C R P C$-reactive protein, $P T H$ parathyroid hormone, IL-17 interleukin-17, DEXA dual energy X-ray absorptiometry, FRAX fracture risk assessment tool

Our results agree with Molnar et al. [16, 17] who investigated serum IL-17A, rank ligand, OPG levels and (BMDs) in 18 pre- and 72 postmenopausal women and reported that IL-17A were elevated in osteoporotic women than in osteopenic ones. They also conveyed the connection between estrogen deficiency and elevated IL17 level in post-menopausal females.

Same results were also reported by AL-Tai [18] who evaluated IL-17 in 84 postmenopausal females and concluded that serum IL-17 was significantly high-up in osteoporotic postmenopausal when compared to healthy postmenopausal women. Furthermore, Zhao et al. [19] reported higher serum concentrations of IL-17, with increased IL17-producing CD4+ T cells, as well as mRNA levels of IL17 in CD4+ T cells in osteoporotic postmenopausal women than postmenopausal healthy controls. Similarly, Waliullah et al. [20] also conveyed a higher level of IL-17 in postmenopausal females with estrogen deficiency.

This is because E2 preserves bone by boosting osteoclasts apoptosis attributed by increased assembly of TGF- $\beta$. In an estrogen shortage, the osteoclasts are enhanced by amplified action of proinflammatory cytokines, as IL-1, IL-6, IL-17, and TNF- $\alpha$, which are adversely operated by estrogen [21]. IL-17 bone loss effect is triggered through RANK ligand-mediated osteoclastogenesis, to generate MCSF and RANKL in osteoblasts and mesenchymal stem cells to boost the growth of bone-resorbing osteoclasts from monocyte/

Table 5 Correlation study between IL-17, E2, and radiological data in postmenopausal women

\begin{tabular}{lllllllll}
\hline & \multicolumn{3}{l}{ Estrogen } & & & IL-17 & & \\
\cline { 2 - 4 } & $\boldsymbol{r}$ & $\boldsymbol{p}$ value & Sig. & & $\boldsymbol{r}$ & $\boldsymbol{p}$ & Sig. \\
\hline DEXA score & 0.584 & 0.001 & HS & & -0.661 & 0.001 & HS \\
FRAX index & -0.679 & 0.001 & HS & 0.639 & 0.001 & HS \\
Estradiol (E2) & & & & -0.665 & 0.001 & HS \\
\hline
\end{tabular}

DEXA dual energy X-ray absorptiometry, FRAX fracture risk assessment tool macrophage precursors. Moreover, Th17 cells (RANKLexpressing T cells) reinforce osteoclastogenesis [22].

De Selm et al. [23] observed that blocking IL-17 signaling prevents estrogen deficiency-mediated osteoporosis by inhibiting osteoclastogenesis in an animal model. Additionally, there was an upsurge in IL-17A producing $\mathrm{T}$ helper 17 cells in BM after ovariectomy of mice, and on providing them with neutralizing IL-17 antibodies; bone loss was no longer deteriorating. While another study established that mice missing the core IL-17 receptor (IL17RA) or its downstream effector protein, Act1, were guarded from the skeletal impacts of ovariectomy [5].

In our study, IL-17was inversely correlated to estrogen level and had a highly significant statistical negative correlation with bone mineral density (DEXA score) as well as a highly significant positive one with FRAX index. These results are in harmony with Molnar et al. [17], Zhang et al. [24], and Waliullah et al. [20], who stated that serum IL-17A levels were higher in postmenopausal patients with osteoporosis, with a significant negative correlation between IL-17A levels and BMD further highlighting the influential role of IL-17 in the pathogenesis of postmenopausal OP.

On performing ROC statistical analysis, IL-17 serum level was able to diagnose osteoporosis at a cutoff level of $>80 \mathrm{pg} / \mathrm{mL}$ with $100 \%$ sensitivity, $100 \%$ specificity, $100 \%$ PPV, and 100\% NPV. To our limited knowledge, this is the earliest study to investigate the diagnostic performance of IL-17 using ROC curve to discriminate osteoporotic from non-osteoporotic postmenopausal females.

In the present study, DEXA score diagnosed osteoporosis at a cutoff level of $\leq 0.875$, with $100 \%$ sensitivity, $100 \%$ specificity, $100 \% \mathrm{PPV}$, and $100 \% \mathrm{NPV}$ and an AUC of 1.0.

As for the FRAX, it can be used to diagnose osteoporosis at a cutoff level of $>0.4$, with $93.33 \%$ sensitivity, $80 \%$ specificity, 82.4\% PPV, and 92.3\% NPV and an AUC of 0.92.

Kripa et al. [25] in their study evaluate various screening tools in determining the risk of osteoporosis in 2000 

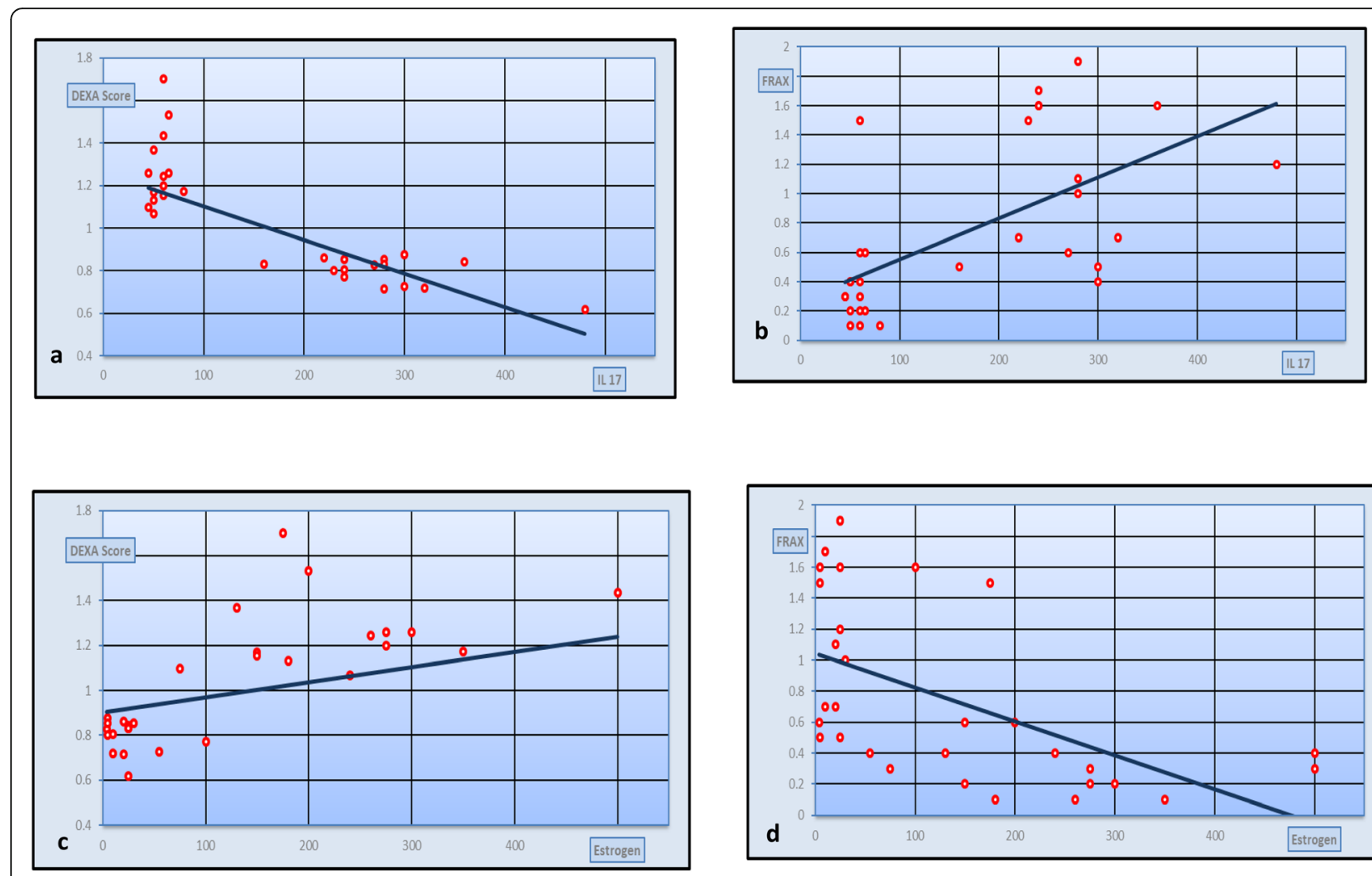

Fig. 1 Correlation study of IL-17 with DEXA score (a) and FRAX index (b). Correlation study of E2 with DEXA score (c) and FRAX index (d)

postmenopausal women concluded that the performance of FRAX $^{\oplus}$ was suboptimal as it was devised to foresee fractures not osteoporosis. They found that at a cutoff level of $\geq$ $0.7 \%$, AUC of 0.736 , FRAX ${ }^{\odot}$ had a sensitivity of $72.7 \%$ and an acceptable specificity $60.5 \%$. Thus, the utilization of straightforward evaluating methods for the spotting of osteoporosis helps in the early distinguishing of women in danger of fracture.

\section{Conclusions}

In conclusion, serum IL-17 was significantly elevated in osteoporotic postmenopausal women when compared to healthy postmenopausal ones. It was also inversely correlated with estrogen level and bone mineral density in these patients. However, our study was limited by disregarding the osteopenic patient, the small population number and narrow geographical scale. So, further studies with enrollment of these limitations are essential to emphasize our conclusion. The results of the present study together with the impact on bone loss witnessed with anti-IL-17A therapies in postmenopausal osteoporosis animal models raise the issue of a distinctive effect of this cytokine on bone. A potential consequence of IL-17A blocking therapies in postmenopausal osteoporosis will be an appealing focus to investigate in future studies.

\section{Abbreviations}

BMD: Bone mineral density; RANKL: Nuclear factor k-B ligand; E2: Estrogen; OPG: Osteoprotegerin; IL-17: Interleukin-17; ADL: Activities of daily living; BMI: Body mineral index; DEXA: Dual energy X-ray absorptiometry; FRAX: Fracture risk assessment tool; ESR: Erythrocyte sedimentation rate; CRP: C-reactive protein; TSH: Thyroid-stimulating hormone; PTH: Parathyroid hormone; ROC: Receiver operating characteristic; PPV: Positive predictive value; NPV: Negative predictive value

\section{Acknowledgments}

Not applicable

\section{Authors' contributions}

NN gave idea and put study design. ER and SA collected the patients' data and analyze them. ER wrote the paper with revision. They all approved the final version of the manuscript.

\section{Funding}

This study had no funding from any resource.

\section{Availability of data and materials}

The datasets used and/or analyzed during the current study are available from the corresponding author on reasonable request.

\section{Declarations}

\section{Ethics approval and consent to participate}

This study was approved by the Ethical Committee of the Faculty of Medicine, Ain Shams University, 29 September 2019; number of approval, MS 318/2019.

All patients included in this study gave written informed consent to participate in this research. 


\section{Consent for publication}

All patients included in this research gave written informed consent to publish the data contained within this study. If the patient was less than 16 years old, deceased, or unconscious when consent for publication was requested, written informed consent for the publication of this data was given by their parent or legal guardian.

\section{Competing interests}

The authors declare that they have no competing interests.

\section{Author details}

'Department of Physical Medicine, Rheumatology, and Rehabilitation, Faculty of Medicine, Ain Shams University, Cairo, Egypt. ²Department of Clinical and Chemical Pathology, Faculty of Medicine, Ain Shams University, Cairo, Egypt.

Received: 21 April 2021 Accepted: 25 August 2021

Published online: 23 November 2021

\section{References}

1. Ji MX, Yu Q (2015) Primary osteoporosis in postmenopausal women. Chronic diseases and translational medicine 1(1):9-13. https://doi.org/10.101 6/j.cdtm.2015.02.006

2. Cauley JA (2015) Estrogen and bone health in men and women. Steroids 99(Pt A):11-15. https://doi.org/10.1016/..steroids.2014.12.010

3. Yi S, Zhang Z, Guo T, Yang R, Jin L, Wenjia L (2019) Postmenopausal osteoporosis: a mini review. EMJ Rheumatol 6(1):90-100

4. Pardhe BD, Pathak S, Bhetwal A, Ghimire S, Shakya S, Khanal PR, Marahatta SB (2017) Effect of age and estrogen on biochemical markers of bone turnover in postmenopausal women: a population-based study from Nepal. International journal of women's health 9:781-788. https://doi.org/10.2147/ IJWH.S145191

5. Scheffler JM, Grahnemo L, Engdahl C, Drevinge C, Gustafsson KL, Corciulo C, Lawenius L, Iwakura Y, Sjögren K, Lagerquist MK, Carlsten H, Ohlsson C, Islander U (2020) Interleukin 17A: a Janus-faced regulator of osteoporosis. Sci Rep 10(1):5692. https://doi.org/10.1038/s41598-020-62562-2

6. Martin JC, Baeten DL, Josien R (2014) Emerging role of IL-17 and Th17 cells in systemic lupus erythematosus. Clin Immunol 154(1):1-12. https://doi. org/10.1016/j.clim.2014.05.004

7. Kim EK, Kwon JE, Lee SY, Lee EJ, Kim DS, Moon SJ et al (2017) IL17 mediated mitochondrial dysfunction impairs apoptosis in rheumatoid arthritis synovial fibroblasts through activation of autophagy. Cell Death Dis 8:e2565

8. Tyagi AM, Srivastava K, Mansoori MN, Trivedi R, Chattopadhyay N, Singh D (2013) Estrogen deficiency induces the differentiation of IL-17 secreting Th17 cells: a new candidate in the pathogenesis of osteoporosis. PLoS One 7(9):e44552

9. Youngkyun $L$ (2013) The role of interleukin-17 in bone metabolism and inflammatory skeletal diseases. BMB Rep. 46(10):479-483

10. Siris ES, Adler R, Bilezikian J, Bolognese M, Dawson-Hughes B, Favus MJ, Harris ST, Jan de Beur SM, Khosla S, Lane NE, Lindsay R, Nana AD, Orwoll ES, Saag K, Silverman S, Watts NB (2014) The clinical diagnosis of osteoporosis: a position statement from the National Bone Health Alliance Working Group. Osteoporos Int 25(5):1439-1443. https://doi.org/10.1007/s00198014-2655-z

11. Katz S, Down TD, Cash HR, Grotz RC (1970) Progress in the development of the index of ADL. The Gerontologist 10(1):20-30. https://doi.org/10.1093/ geront/10.1_Part_1.20

12. Kanis JA (2007) on behalf of the World Health Organization Scientific Group. Technical Report. World Health Organization Collaborating Centre for Metabolic Bone Diseases, University of Sheffield; UK: 2007. 2007. Assessment of osteoporosis at the primary health-care level.

13. Kanis JA, Hans D, Cooper C, Baim S, Bilezikian JP, Binkley N et al (2011) Interpretation and use of FRAX in clinical practice. Osteoporos Int. 22(9): 2395-2411. https://doi.org/10.1007/s00198-011-1713-z

14. Veldhoen A (2017) Interleukin 17 is a chief orchestrator of immunity. Nat. Immunol. 18(6):612-621. https://doi.org/10.1038/ni.3742

15. Korayem HK, Rezk MM, Hassan MM, El-Tawab SS, Elsaid NA (2016) Relation between serum IL-17 level and risk of osteoporotic fracture in premenopausal rheumatoid arthritis patients: clinical, radiological and laboratory studies. The Egyptian Rheumatologist. 38(2):85-90. https://doi org/10.1016/j.ejr.2015.06.006
16. Molnár I, Bohaty I, Somogyiné-Vári E (2014) High prevalence of increased interleukin-17A serum levels in postmenopausal estrogen deficiency. Menopause. 21(7):749-752. https://doi.org/10.1097/GME.0000000000000125

17. Molnar I, Bohaty I, Somogyine-Vari E (2014) IL-17A-mediated sRANK ligand elevation involved in postmenopausal osteoporosis. Osteoporosis International. 25(2):783-786. https://doi.org/10.1007/s00198-013-2548-6

18. AL-Tai, TH. (2015) Serum IL-17 and postmenopausal osteoporosis. Journal of the Faculty of Medicine Baghdad 57(4):299-301. https://doi.org/10.32007/ med.1936/jfacmedbagdad.v57i4.9

19. Zhao R, Wang X, Feng F (2016) Upregulated cellular expression of IL-17 by CD4+ T-cells in osteoporotic postmenopausal women. Annals of Nutrition and Metabolism 68(2):113-118. https://doi.org/10.1159/000443531

20. Waliullah S, Sharma V, Srivastava RN, Pradeep Y, Mahdi AA, Kumar S (2018) IL-17A and IL-23 cytokines and their relation with estrogen in postmenopausal osteoporosis. International Journal of Orthopedics 4(1):864-866

21. Pietschmann $P$, Mechtcheriakova D, Meshcheryakova A, Föger-Samwald $U$, Ellinger I (2016) Immunology of osteoporosis: a mini-review. Gerontology. 62(2):128-137. https://doi.org/10.1159/000431091

22. Benoit Le Goff, Béatrice B, Thierry L, Eric L, Hubert M., Yves-Marie P., and Bernard C. (2019): Implication of IL-17 in bone loss and structural damage in inflammatory rheumatic diseases. Mediators of Inflammation; Volume 2019, Article ID 8659302

23. DeSelm CJ, Takahata Y, Warren J, Chappel JC, Khan T, Li X, Teitelbaum SL (2012) IL-17 mediates estrogen-deficient osteoporosis in an Act1-dependent manner. Journal of cellular biochemistry 113(9):2895-2902. https://doi.org/1 $0.1002 / j c b .24165$

24. Zhang J, Fu Q, Ren Z, Wang Y, Wang C, Shen T, Wu L (2015) Changes of serum cytokines- related Th1/Th2/Th17 concentration in patients with postmenopausal osteoporosis. Gynecological Endocrinology 31(3):183-190. https://doi.org/10.3109/09513590.2014.975683

25. Kripa EC, Nitin K, Sahana S, Dukhabandhu N, Nihal T, Thomas VP (2018): Evaluation of different screening tools for predicting femoral neck osteoporosis in rural South Indian postmenopausal women, Journal of Clinical Densitometry, Volume 21, Issue 1.

\section{Publisher's Note}

Springer Nature remains neutral with regard to jurisdictional claims in published maps and institutional affiliations.

\section{Submit your manuscript to a SpringerOpen ${ }^{\odot}$ journal and benefit from:}

- Convenient online submission

- Rigorous peer review

- Open access: articles freely available online

High visibility within the field

- Retaining the copyright to your article

Submit your next manuscript at $>$ springeropen.com 